\title{
Atrioventricular block after ASD closure
}

\author{
Hiroko Asakai, 1,2,3 Sofia Weskamp, 1,2 Lucas Eastaugh, 1,2 Yves d'Udekem, 2,4 \\ Andreas Pflaumer ${ }^{1,2}$
}

'Department of Cardiology, Royal Children's Hospital, Heart Research Group, Murdoch Childrens Research Institute, Melbourne, Victoria, Australia

${ }^{2}$ Department of Pediatrics, University of Melbourne, Melbourne, Victoria, Australia ${ }^{3}$ Department of Pediatrics, University of Tokyo Hospital, Tokyo, Japan

${ }^{4}$ Department of Cardiac Surgery, Royal Children's Hospital, Heart Research Group, Murdoch Childrens Research Institute, Melbourne, Victoria, Australia

\section{Correspondence to}

Dr Andreas Pflaumer, Department of Cardiology, Royal Children's Hospital, Melbourne, 50 Flemington Road, Parkville, VIC 3052,

Australia;

andreas.pflaumer@rch.org.au

Received 11 March 2016 Revised 9 July 2016 Accepted 11 July 2016

\section{CrossMark}

To cite: Asakai $\mathrm{H}$, Weskamp S, Eastaugh L, et al. Heart Asia 2016;8:2631. doi:10.1136/heartasia2016-010745

\begin{abstract}
Objective Secundum atrial septal defect (ASD) is a common congenital heart defect. There is limited data on both early and late atrioventricular (AV) block post ASD closure. The aim of this study was to determine the incidence and risk factors of AV block associated with ASD closure.

Methods A retrospective analysis of all patients who underwent ASD closure either with a device or surgical method at the Royal Children's Hospital Melbourne between 1996 and 2010 was performed. Baseline demographics, procedural details and follow-up data were collected from medical records.
\end{abstract}

Results A total of 378 patients were identified; 242 in the device group and 136 in the surgical group. Fourteen patients (3.7\%) had AV block (1 with second degree and 13 with first degree) at a median follow-up of 28 months; $11 / 242(4.5 \%)$ in the device group and $3 / 135(2.2 \%)$ in the surgical group $(p=0.39)$. Six patients had new-onset AV block after ASD closure. In the device subgroup, patients with AV block at follow-up had a larger indexed device size compared with those without (22 (15-31) vs $18(7-38), p=0.02$ ). Multivariate analysis revealed the presence of AV block either pre procedure or post procedure to be the only variables associated with late AV block.

Conclusions Late AV block in patients with repaired ASD is rare and most likely independent of the technique used. In the device subgroup, the only risk factor identified to be associated with late AV block was the presence of either preprocedural or postprocedural AV block, so long-term follow-up for these patients should be provided.

\section{BACKGROUND}

Secundum atrial septal defect (ASD) is the third most common congenital heart defect with an incidence of 3-9 per 10000 live births, accounting for approximately $6-10 \%$ of all congenital cardiac defects. ${ }^{1-3}$ Transcatheter device closure is one of the standard treatments and can be safely performed. However, there are several complications associated with the procedure including arrhythmia, device embolisation, thrombus formation and pericardial effusion. ${ }^{4}$ Transcatheter device closure of ventricular septal defects is known to be associated with late atrioventricular (AV) block, ${ }^{5}$ which raises the concern of the effect of an ASD device on AV conduction particularly since ASD in itself is associated with AV conduction disease. ${ }^{6}$ There is limited data regarding the mechanisms and risk factors for AV block associated with ASD device closure. The aim of this study was to determine the incidence and risk factors of AV block associated with ASD closure.

\section{MATERIALS AND METHODS \\ Patient selection}

A retrospective review of all patients who underwent either transcatheter device closure or surgical closure of a secundum ASD at the Royal Children's Hospital Melbourne between January 1996 and December 2010 was performed. The start date of data collection was when transcatheter device ASD closure was started at our institution. Patients with the following conditions were excluded: (1) the presence of associated congenital cardiac anomalies requiring surgical repair, (2) primum ASD; (3) sinus venosus ASD (including partial anomalous pulmonary venous drainage); and (4) Holt-Oram disease.

Patient demographics, procedural details and follow-up data were collected from the medical records and departmental database. The study was approved by the Royal Children's Hospital Human Research Ethics Committee, and the procedures followed were in accordance with institutional guidelines for retrospective record review and protection of patient confidentiality. The need for patient consent was waived.

\section{ECG evaluation}

The ECG at three time points was reviewed (1) immediately prior to ASD closure, (2) immediately post ASD closure and (3) latest follow-up. For each ECG, the PR and RR intervals were manually measured by one experienced paediatric cardiologist who was blinded to the mode of treatment. A PR interval exceeding the upper limits of normal for a given age and heart rate was defined as first-degree AV block. ${ }^{7}$

\section{Catheter devices and implantation techniques}

Over the study period, two different devices were used: the Amplatzer Septal Occluder (ASO; AGA Medical, Golden Valley, Minnesota) and the GORE HELEX septal occluder (HELEX, W. L. Gore \& Associates, Flagstaff, Arizona). The ASO is a selfcentring device composed of a Nitinol wire mesh with polyester fabric sewn into the discs. The device consists of two self-expandable discs with a connecting waist that dictates the device diameter. Various sizes ranging from 4 to $38 \mathrm{~mm}$ are available in increments of $1-2 \mathrm{~mm}$. The HELEX device is a non-self-centring device made of a single Nitinol wire frame covered with expanded polytetrafluoroethylene. The device sizes available range from 15 to $35 \mathrm{~mm}$ in increments of $5 \mathrm{~mm}$.

All procedures were performed under general anaesthesia. A standard right heart catheterisation was performed, taking recordings of pressures and blood samples to measure oxygen saturations. Heparin $(100 \mathrm{IU} / \mathrm{kg})$ and antibiotic prophylaxis 


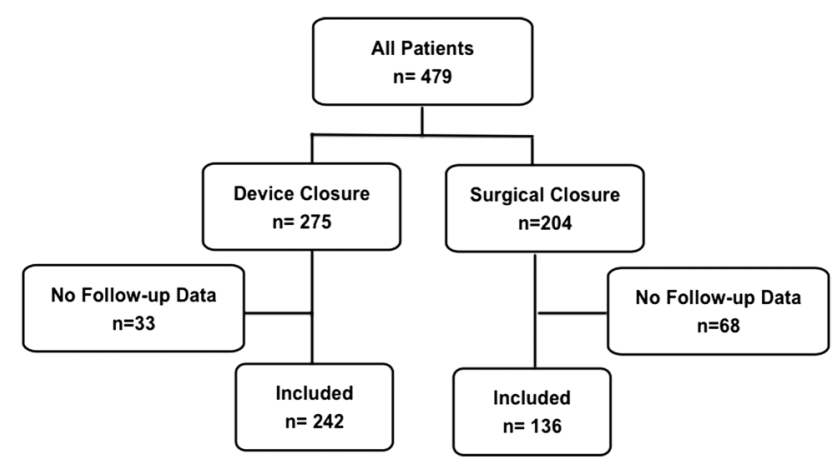

Figure 1 Patient inclusion.

were given routinely. A transoesophageal echocardiogram (TOE) was performed to evaluate the number, position and size of ASDs and surrounding rims. The defects were balloon-sized using a stop-flow technique with either the Meditech Occlusion Balloon Catheter (Boston Scientific, Watertown, Massachusetts) or Amplatzer Sizing Balloon (AGA Medical). The device selected was dependent upon physician preference and anatomical factors; a HELEX device was more likely to be used for defects with deficient retroaortic rims or multifenestrated defects. Device size selection was based on manufacturer recommendations; the ASO device size was up to 1-2 mm larger than the stop-flow balloon diameter and the HELEX device was chosen with a disc size 1.75-2 times greater. The technique for implantation of each device type was performed as recommended by the manufacturer and involved the initial deployment of one disc on the left atrial side of the defect followed by deployment of the second disc on the right atrial side. TOE guidance was used to confirm cessation of flow across the ASD and the balloon size on X-ray was compared with that on ultrasound to determine the most accurate defect size. The cardiac rhythm was also closely monitored to ensure no new ECG changes were present prior to final release of the device.
Patients were usually observed overnight with cardiac monitoring.

\section{Surgical techniques}

Standard surgical ASD closure was performed under general anaesthesia. The right atrium was opened after a sternotomy. The ASD was closed either by direct suture or by using a pericardial patch. Patients were discharged home after an average of 4 days in hospital.

\section{Statistical analysis}

The primary outcome was the presence of $\mathrm{AV}$ block at latest follow-up. Continuous variables were summarised as median and range (minimum to maximum) and categorical variables were summarised as number of cases and percentage. Comparison between the two groups was performed using a Fisher's exact test or Mann-Whitney test as appropriate. In the device subgroup, risk factors associated with follow-up AV block were analysed by univariable conditional logistic regression. All variables entered into the univariable analysis were selected on clinical grounds. Of these, variables with a $\mathrm{p}$ value $<0.20$ under univariable modelling were considered for entry into the multivariable model. All statistical analyses were performed using the statistical package SPSS (IBM, V.20).

\section{RESULTS}

\section{Demographics and baseline characteristics}

Between January 1996 and December 2010, a total of 479 patients underwent ASD closure at our institution; 275 patients (57\%) had transcatheter device closure (device group) and 204 patients (43\%) had surgical closure (surgical group). Follow-up data were available in 378 patients; 242 (65\%) in the device group and $136(35 \%)$ in the surgical group (figure 1). In total, 102 patients were either discharged from follow-up or had been referred back to the local cardiologists. The patients without follow-up data at our centre were excluded from the study. The baseline patient characteristics are described in table 1.

Table 1 Patient demographics

\begin{tabular}{|c|c|c|c|c|}
\hline & $\begin{array}{l}\text { Total } \\
\mathrm{n}=378\end{array}$ & $\begin{array}{l}\text { Catheter } \\
\mathrm{N}=242\end{array}$ & $\begin{array}{l}\text { Surgical } \\
N=136\end{array}$ & p Value \\
\hline \multicolumn{5}{|l|}{ Demographics } \\
\hline Male gender & $146 / 378(38.6 \%)$ & 90/242 (37\%) & $56 / 136(41 \%)$ & NS \\
\hline Down syndrome & $18 / 378(4.8 \%)$ & $12 / 242(5 \%)$ & $6 / 136(4 \%)$ & NS \\
\hline \multicolumn{5}{|l|}{ Number of ASDs } \\
\hline Single & $341 / 378(90 \%)$ & 220/242 (90\%) & $121 / 136(89 \%)$ & NS \\
\hline Multiple & $37 / 378(10 \%)$ & $22 / 242(10 \%)$ & 15/136 (11\%) & \\
\hline Size of ASD (mm) & $14(4-30)$ & $13(4-27)$ & $18(6-30)$ & $<0.0001$ \\
\hline Preprocedure AVB & $31 / 378(8 \%)$ & $21 / 242(8 \%)$ & $10 / 136(7 \%)$ & NS \\
\hline \multicolumn{5}{|l|}{ Procedure variables } \\
\hline Age at procedure (years) & $4(0-18)$ & $5(0-18)$ & $4(0-17)$ & 0.016 \\
\hline BW at procedure $(\mathrm{kg})$ & $18(4.5-95)$ & $19(5.8-78)$ & $15.5(4.5-95)$ & 0.001 \\
\hline $\mathrm{BH}$ at procedure $(\mathrm{cm})$ & $107(58-179)$ & $110(60-179)$ & $104(58-178)$ & 0.013 \\
\hline Postprocedure AVB & $20 / 378(5 \%)$ & $15 / 242(6 \%)$ & $5 / 136(4 \%)$ & NS \\
\hline \multicolumn{5}{|l|}{ Follow-up variables } \\
\hline Age at follow-up (years) & $9(1-21)$ & $10(1-21)$ & $7(1-20)$ & 0.007 \\
\hline Duration of follow-up (months) & $28(1-193)$ & $37(1-193)$ & $18(1-172)$ & 0.007 \\
\hline AVB at follow-up & $14 / 378(4 \%)$ & $11 / 242(5 \%)$ & $3 / 136(2 \%)$ & NS \\
\hline Other arrhythmias at follow-up & $3 / 378(0.8 \%)$ & $2 / 242(0.8 \%)$ & $1 / 136(0.7 \%)$ & NS \\
\hline
\end{tabular}




\section{Original research}

Thirty-one patients $(8.2 \%)$ had first-degree AV block prior to ASD closure; $21 / 242(8 \%)$ in the device group and 10/36 (7\%) in the surgical group. In the device group, there were 190/242 (78.5\%) patients who had an ASO device and 52/242 (21.5\%) patients who had a HELEX device.

\section{AV block at follow-up}

The median duration of follow-up was 28 months (range 1-193 months), with the device group having a longer follow-up than the surgical group (37 months (1-193) vs 18 (1-172) months, $\mathrm{p}=0.005$ ). The median age at follow-up was 9 years (range $1-21$ years); 10 (1-21) years in the device group and 7 (1-20) years in the surgical group $(p=0.001)$. The change in prevalence of $\mathrm{AV}$ block in the entire cohort is shown in figure 2. There were 14 patients (3.7\%) who had AV block at follow-up; $11 / 242(4.5 \%)$ in the device group and $3 / 135(2.2 \%)$ in the surgical group $(p=0.39)$. Of these, six patients had new onset of AV block after ASD closure; five in the device group and one in the surgical group. None of the patients had any symptoms or haemodynamic compromise requiring ASD device removal or permanent pacemaker implantation. Of the 14 patients, only 1 patient had second-degree AV block. The patient with seconddegree AV block was asymptomatic and did not require any treatment. The clinical details of all 14 patients are described in table 2. More than half of the patients $(8 / 14,57 \%)$ had firstdegree AV block prior to ASD closure, which was a significantly higher prevalence compared with $23 / 364(6 \%)$ in patients who did not have AV block at follow-up $(p<0.05)$. Other baseline characteristics as well as procedural variables did not differ between the patients with AV block and without AV block at follow-up (table 3). There was only one patient with other significant arrhythmias at follow-up. This patient was known to have supraventricular tachycardia prior to ASD closure and underwent a catheter ablation for atrioventricular nodal re-entrant tachycardia.

Out of the 31 patients who had AV block prior to ASD closure, 23 patients (74\%) had resolution of $\mathrm{AV}$ block at follow-up (figure 2).

\section{AV block in the device closure subgroup}

Of the 242 patients who underwent device closure, 11/242 (4.5\%) had AV block at follow-up; 10 patients had first-degree and 1 patient had second-degree AV block. Six patients had
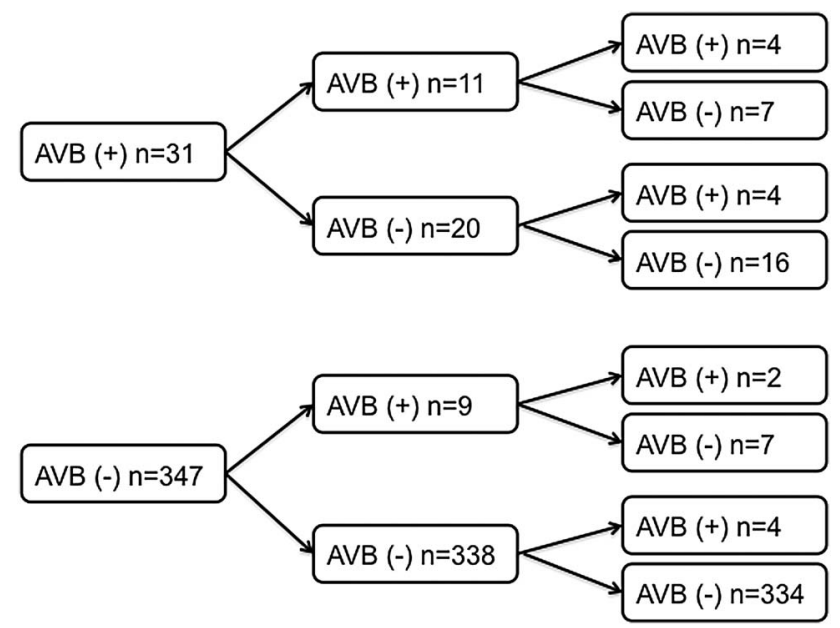

Figure 2 Prevalence of atrioventricular block (AVB).

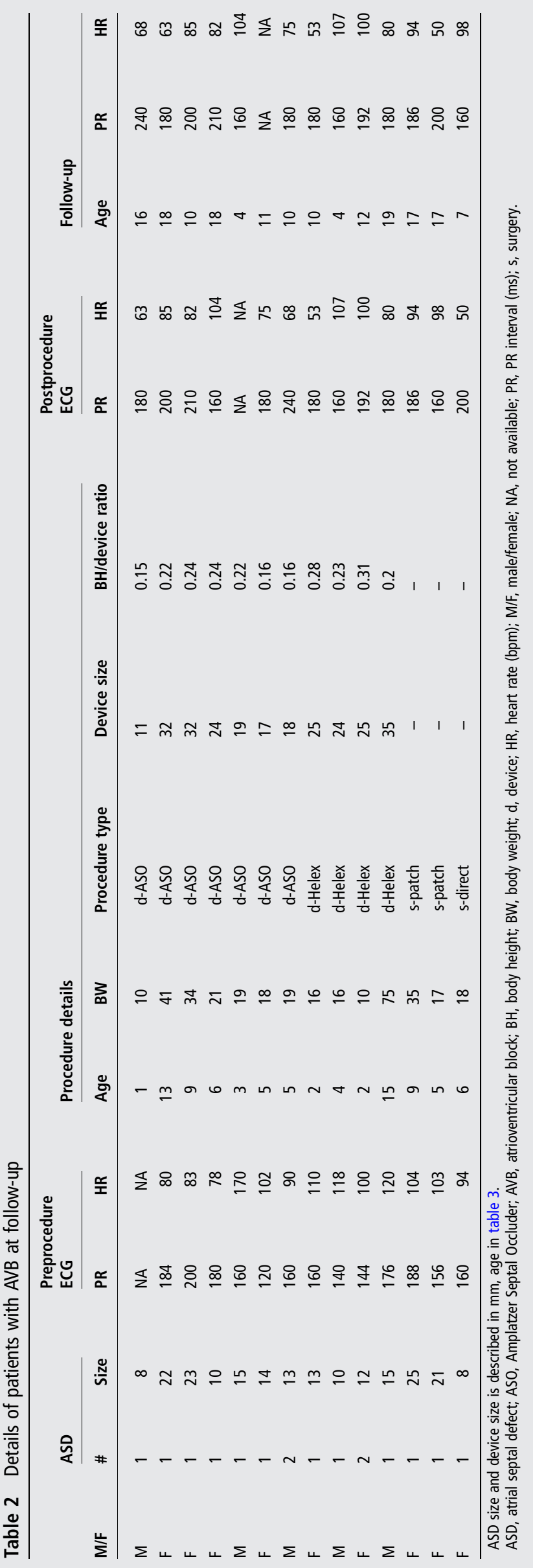


Table 3 Comparison between patients with AVB at follow-up

\begin{tabular}{|c|c|c|c|c|}
\hline & $\begin{array}{l}\text { Total } \\
\mathrm{n}=378\end{array}$ & $\begin{array}{l}\text { AVB }(+) \\
n=14\end{array}$ & $\begin{array}{l}\text { AVB (-) } \\
n=364\end{array}$ & $\mathrm{p}$ Value \\
\hline \multicolumn{5}{|l|}{ Demographics } \\
\hline Male gender & 146/378 (38.6\%) & $5 / 14(36 \%)$ & 141/364 (39\%) & NS \\
\hline Down syndrome & $18 / 378(4.8 \%)$ & $2 / 14(14 \%)$ & $16 / 364(4 \%)$ & 0.097 \\
\hline Multiple ASDs & $37 / 378(9.8 \%)$ & $2 / 14(16.7 \%)$ & $35 / 364(9.6 \%)$ & NS \\
\hline Size of ASD (mm) & $14(4-30)$ & $13.5(8-25)$ & $14(4-30)$ & NS \\
\hline Preprocedure AVB & $31 / 378(8 \%)$ & $8 / 14(57 \%)$ & 23/364 (6\%) & $<0.0001$ \\
\hline \multicolumn{5}{|l|}{ Procedure variables } \\
\hline Age at procedure (years) & $4(0-18)$ & $5(1-15)$ & $4(0-18)$ & NS \\
\hline BW at procedure (kg) & $18(4.5-95)$ & $18.5(10-75)$ & $18(4.5-90)$ & NS \\
\hline $\mathrm{BH}$ at procedure $(\mathrm{cm})$ & $107(58-179)$ & $106(73-179)$ & $107(58-178)$ & NS \\
\hline Catheter closure & $242 / 378(64 \%)$ & $11 / 14(79 \%)$ & $231 / 364(64 \%$ & NS \\
\hline \multicolumn{5}{|l|}{ Device details } \\
\hline \multicolumn{5}{|l|}{ Device type } \\
\hline ASO & 190/242 (79\%) & $7 / 11(64 \%)$ & 183/231 (79\%) & NS \\
\hline Helex & $52 / 242(21 \%)$ & $4 / 11(36 \%)$ & $48 / 231(21 \%)$ & \\
\hline \multicolumn{5}{|l|}{ Number of device } \\
\hline 1 & $236 / 242(97 \%)$ & $11 / 11(100 \%)$ & 225/231 (97\%) & NS \\
\hline 2 & $6 / 242(3 \%)$ & $0 / 11(0 \%)$ & 6/231 (3\%) & \\
\hline Device size $(\mathrm{mm})$ & $20(8-35)$ & $24(11-35)$ & $20(8-35)$ & 0.076 \\
\hline $\mathrm{BH} /$ device ratio $(\mathrm{cm} / \mathrm{mm})$ & $0.18(0.07-0.38)$ & $0.22(0.15-0.31)$ & $0.18(0.07-0.38)$ & 0.022 \\
\hline Postprocedure AVB & 20/378 (5\%) & $6 / 14(43 \%)$ & $14 / 364(4 \%)$ & $<0.0001$ \\
\hline \multicolumn{5}{|l|}{ Follow-up variables } \\
\hline Age at follow-up (years) & $9(1-21)$ & $11.5(4-19)$ & $9(1-21)$ & 0.037 \\
\hline Follow-up duration (months) & $28(0-193)$ & 70 (6.4-189) & $27(0-193)$ & 0.018 \\
\hline
\end{tabular}

Table 4 Risk factors associated with follow-up AVB in the device closure subgroup

\begin{tabular}{|c|c|c|c|c|c|c|c|c|}
\hline \multirow[b]{3}{*}{ Risk factors } & \multicolumn{4}{|c|}{ Univariate analysis } & \multicolumn{4}{|c|}{ Multivariate analysis } \\
\hline & \multirow[b]{2}{*}{ OR } & \multicolumn{2}{|l|}{$\mathrm{Cl}$} & \multirow[b]{2}{*}{$\mathrm{p}$ Value } & \multirow[b]{2}{*}{ OR } & \multicolumn{2}{|l|}{$\mathrm{Cl}$} & \multirow[b]{2}{*}{ p Value } \\
\hline & & Lower & Upper & & & Lower & Upper & \\
\hline \multicolumn{9}{|l|}{ Demographics } \\
\hline Male gender & 1.43 & 0.43 & 4.83 & NS & & & & \\
\hline Down syndrome & 4.87 & 1.93 & 25.60 & 0.10 & 1.23 & 0.10 & 15.27 & NS \\
\hline Multiple ASDs & 2.34 & 0.47 & 11.61 & NS & & & & \\
\hline Preprocedure AVB & 18.60 & 5.00 & 68.50 & 0.00 & 7.92 & 1.32 & 47.35 & 0.02 \\
\hline \multicolumn{9}{|l|}{ Procedure variables } \\
\hline ASO device & 2.18 & 0.61 & 7.75 & NS & & & & \\
\hline Multiple device & 0.97 & 0.95 & 1.00 & NS & & & & \\
\hline Device size (mm) & 1.09 & 1.00 & 1.20 & 0.06 & 1.00 & 0.86 & 1.15 & NS \\
\hline BH/device ratio $(\mathrm{m} / \mathrm{mm})$ & 1.12 & 1.01 & 1.23 & 0.03 & 1.15 & 0.97 & 1.35 & NS \\
\hline Postprocedure AVB & 29.60 & 7.50 & 115.40 & 0.00 & 9.84 & 1.52 & 63.46 & 0.02 \\
\hline
\end{tabular}

ASD, atrial septal defect; ASO, Amplatzer Septal Occluder; AVB, atrioventricular block; BH, body height; NS, not significant.

preprocedural AV block and five patients developed AV block post device closure, with three patients developing AV block only at follow-up. The patients who had AV block at follow-up had a larger indexed device size (device size/body height ratio, $\mathrm{mm} / \mathrm{m}$ ) (22 (15-31) vs $18(7-38), \mathrm{p}=0.02)$. Device type, number of device and device size were similar among the two groups (table 3). With univariate analysis, preprocedural and postprocedural AV block as well as indexed device size appeared to be associated with follow-up AV block; however, with multivariate analysis, the presence of AV block either prior to or post procedure were the only variables associated with follow-up AV block (table 4).

\section{DISCUSSION}

Device closure versus surgical closure

Both device closure and surgical closure is a safe procedure with very low mortality and complication rate. A comparison of the US Food and Drug Administration Manufacturer and User Facility Device Experience database and the Society of Thoracic Surgery congenital cardiac surgery database demonstrated the overall mortality for device and surgical closure to be equivalent $(0.093 \%$ vs $0.13 \%, \mathrm{p}=0.649) .{ }^{4}$ However, in a large multicentre non-randomised trial of 442 patients including both children and adults, the complication rate was lower and the length of 
hospital stay was shorter in device closure than for surgical repair. ${ }^{8}$ Arrhythmias and conduction abnormalities were the most common complications, seen in 17/442(3.9\%) in the device group and 9/154 (5.9\%) in the surgical group. However, most of these arrhythmias were transient with only one paediatric case requiring a permanent pacemaker implantation for $\mathrm{AV}$ block. In our cohort, the prevalence of postprocedural AV block was $5 \%$ in the device group and $2 \%$ in the surgical group, which is comparable to the reported prevalence. However, the follow-up period was shorter in the surgical group and this may have influenced the difference in the prevalence.

\section{Device closure and AV block}

Transcatheter device closure of ASDs has become an alternative to surgical closure requiring cardiopulmonary bypass. Although considered a highly effective and low-risk procedure, complications such as device erosion, embolisation/malposition and arrhythmias have been previously reported.$^{8-13}$ In particular, AV block following device closure is an important risk factor as it may cause long-term effect on patient care. AV block related to device closure is reported to be rare, ${ }^{8}{ }^{12}{ }^{14-16}$ and most have been transient. ${ }^{15}{ }^{17}$ However, there are several case reports of complete AV block post device closure requiring removal of the device and surgical closure of the ASD. ${ }^{18} 19$

Chessa and colleagues reported a complication rate of $8.6 \%$ of which arrhythmia was the second common complication occurring in $11 / 417(2.6 \%)$ patients in a cohort of 417 patients who had device closure using either a CardioSEAL/STARFlex or an Amplatzer Septal Occulder. Most patients had atrial fibrillation or supraventricular tachycardia, and only one patient had complete AV block immediately after device implantation with complete recovery of $\mathrm{AV}$ conduction 3 hours after device removal. $^{12}$

In a large single-centre cohort of 610 patients (including adults) who underwent ASD and persistent foramen ovale (PFO) closure with a device, there were two patients who developed complete AV block; one patient with preprocedure intermittent second-degree AV block and one 16-year-old patient with previously repaired double outlet right ventricle who had a device closure of a residual ASD 2 weeks after right ventricularpulmonary artery conduit. This was the only paediatric case ( $<21$ years of age) with postprocedure arrhythmia. The incidence of short-term postprocedure arrhythmia in the adult patients ( $>21$ years of age) was $5.6 \%(31 / 557) .{ }^{20}$

Wang reported an incidence of AV block to be $0.85 \%(6 / 706$ patients) in patients who had device closure. All AV blocks occurred within 24 hours after the procedure. They identified younger age, larger ASD size, larger device size and larger device diameter to septum diameter ratio to be associated with AV block. In particular, all patients with second-degree or higher AV block were under the age of 3.5 years. Patients with first-degree AV block recovered with time and no patient developed progressive AV block during follow-up. The two patients with complete AV block both had device removal; one patient recovered to sinus rhythm immediately after device removal, but one patient had persistent $\mathrm{AV}$ conduction disturbance at follow-up, although the details are not described in the paper. $^{17}$

\section{AV block at follow-up}

Suda and colleagues reported 6.2\% (10/162 patients) with new-onset or aggravation of AV block following ASD closure with ASO. The AV block occurred within 1 week of procedure with spontaneous resolution or improvement observed in all patients. Device size $\geq 19 \mathrm{~mm}$ or indexed device size $\geq 0.18 \mathrm{~mm} / \mathrm{cm}$ was the major predisposing factor. ${ }^{15}$ In our cohort, only the indexed device size was associated with AV block at follow-up. The mechanism of AV block after device closure remains uncertain. The location of the ASD and the rim characteristics may be an important factor; however, these details were not collected in our current study. We can only postulate that a larger device can potentially pressure and damage the AV node itself.

There are several reports of changes in Holter monitor findings pre device and post device closure of ASD. Hill and colleagues analysed ambulatory Holter monitoring pre ASD closure and immediately post ASD closure with ASO in 41 patients. There were three patients $(7 \%)$ who demonstrated changes in $\mathrm{AV}$ conduction, with one patient who developed complete AV dissociation requiring a pacemaker implantation. Overall, there was no change in PR interval pre procedure and post procedure. ${ }^{16}$ Hessling and colleagues performed 24 hour Holter monitoring before and 1 year after ASD closure using an ASO in 23 paediatric patients. There were no AV conduction disturbances observed in this study. ${ }^{21}$ In an adult study, the PR interval increased post ASD device closure after a mean follow-up period of 4 years. $^{22}$

Interestingly, resolution of arrhythmias following ASD closure has also been reported. Wilson and colleagues reported 227 adults and children who underwent ASD closure with ASO in a single centre in New Zealand. ${ }^{23}$ There were 24 patients who had preprocedure arrhythmias, of which 16 resolved following ASO. Schenck and colleagues studied 18 patients who underwent ASD closure with the Bard Clamshell Septal Umbrella with a Holter and ECG, and demonstrated that there was improvement of first-degree AV block in $2 / 3$ patients. $^{24}$ Similarly, in our cohort close to $75 \%$ of the patients who had preprocedural AV block had resolution at follow-up.

\section{STUDY LIMITATIONS}

This study is limited to a single-centre non-randomised cohort of patients with ASD. The device closure and surgical closure groups were not comparable in age and size of the ASD. The disparity is mainly due to patient selection as patients with large ASDs would most likely be not suitable for device closure and

\section{Key messages}

What is already known about this subject?

Atrioventricular (AV) block is a known complication for patients with atrial septal defect (ASD). There are case reports of AV block following transcatheter device closure of ASDs, and this is a known complication.

What does this study add? AV block post ASD repair can occur regardless of repair type (device vs surgical). The incidence of AV block at follow-up is low at $2-4 \%$, and the majority of cases had $\mathrm{AV}$ block prior to procedure.

How might this impact on clinical practice? Although patients with ASD post closure (either surgical or device) do not often receive long-term follow-up, given the risk of developing late AV block, longer follow-up is recommended in particular with patients who have AV block prior to or immediately after ASD closure. 
would have had surgical closure. A substantial number of patients were excluded due to lack of follow-up data, which may result in a potential selection bias. There may be interobserver variability in the ECG analysis as it was performed by a single cardiologist.

\section{CONCLUSION}

The prevalence of AV block in patients with repaired ASD is low and rarely requires medical management. However, there are rare cases of late-onset AV block. The presence of either preprocedural or postprocedural AV block was the only risk factor identified to be associated with follow-up AV block in the device subgroup. Previously reported risk factors such as device size and indexed device size were not identified to be significantly associated with late AV block.

Contributors HA has contributed to the design of the study, data collection, data analysis and drafting of the manuscript. SW has contributed to the design of the study and data collection. AP has contributed to the design of the study, overseeing of the study, revision and approval of the manuscript. Both LE and Yd'U have contributed to the revision of the manuscript.

Competing interests None declared.

Ethics approval Royal Children's Hospital Human Research Ethics Committee.

Provenance and peer review Not commissioned; externally peer reviewed.

\section{REFERENCES}

1 Dickinson DF, Arnold R, Wilkinson JL. Congenital heart disease among 160480 liveborn children in Liverpool 1960 to 1969. British Heart Journal 1981;46:55-62.

2 Hoffman JIE, Kaplan S. The incidence of congenital heart disease. JACC 2002;39:1890-900.

3 Mitchell SC, Korones SB, Berendes HW. Congenital heart disease in 56,109 Births. Circulation 1971;43:323-32.

4 DiBardino DJ, McElhinney DB, Kaza AK, et al. Analysis of the US Food and Drug Administration Manufacturer and User Facility Device Experience database for adverse events involving Amplatzer septal occluder devices and comparison with the Society of Thoracic Surgery congenital cardiac surgery database. JTCS 2009;137:1334-41.

5 Bai Y, Xu X-D, Li C-Y, et al. Complete atrioventricular block after percutaneous device closure of perimembranous ventricular septal defect: a single-center experience on 1046 cases. HRTHM 2015;12:2132-40.

6 Shiku DJ, Stijns M, Lintermans JP, et al. Influence of age on atrioventricular conduction intervals in children with and without atrial septal defect. J Eletrocardiol 1982:15:9-13.

7 Rijnbeek P. New normal limits for the paediatric electrocardiogram. Eur Heart $J$ 2001:22:702-11.
8 Du Z-D, Hijazi ZM, Kleinman CS, et al. Comparison between transcatheter and surgical closure of secundum atrial septal defect in children and adults. Journa of the American College of Cardiology 2002;39:1836-44.

9 Masura J, Gavora P, Podnar T. Long-term outcome of transcatheter secundum-type atrial septal defect closure using Amplatzer septal occluders. JACC 2005;45:505-7.

10 Wilson NJ, Smith J, Prommete B, et al. Transcatheter closure of secundum atria septal defects with the amplatzer septal occluder in adults and children-follow-up closure rates, degree of mitral regurgitation and evolution of arrhythmias. Heart, Lung and Circulation 2008;17:318-24.

11 Berger F, Vogel M, Alexi-Meskishvili V, et al. Comparison of results and complications of surgical and amplatzer device closure of atrila septal defects. JTCS 1999:118:674-80.

12 Chessa M, Carminati M, Butera G, et al. Early and late complications associated with transcatheter occlusion of secundum atrila septal defect. JACC 2002;39:1061-5.

13 Hijazi ZM. Catheter closure of atria1 septal and ventricular septal defects using the amplatzer devices. Heart, Lung and Circulation 2003:12(Suppl 2):63-72.

14 Nehgme RA, Huddleston AR, Cheatham JP. Progression to late complete atrioventricular block following amplatzer device closure of atrial septal defect in a child. Pediatric Cardiology 2008;30:367-70.

15 Suda K, Raboisson M-J, Piette E, et al. Reversible atrioventricular block associated with closure of atrial septal defects using the amplatzer device. JACC 2004;43:1677-82.

16 Hill SL, Berul $\mathrm{Cl}$, Patel $\mathrm{H}$, et al. Early ECG abnormalities associated with transcatheter closure of atrial septal defects using the amplatzer. J Interv Card Electrophysiol 2000;4:469-74.

17 Wang Y, Hua Y, Li L, et al. Risk factors and prognosis of atrioventricular block after atrial septum defect closure using the amplatzer device. Pediatric Cardiology 2013;35:550-5

18 Al-Anani SJ, Weber H, Hijazi ZM. Atrioventricular block after transcatheter ASD closure using the Amplatzer septal occluder: risk factors and recommendations. Cathet Cardiovasc Intervent 2009:75:767-72.

19 Clark JB, Chowdhury D, Pauliks LB, et al. Resolution of heart block after surgical removal of an amplatzer device. The Annals of Thoracic Surgery 2010;89:1631-3.

20 Johnson JN, Marquardt ML, Ackerman MJ, et al. Electrocardiographic changes and arrhythmias following percutaneous atrial septal defect and patent foramen ovale device closure. Cathet Cardiovasc Intervent 2011;78:254-61.

21 Hessling G, Hyca S, Brockmeier K, et al. Cardiac dysrhythmias in pediatric patients before and 1 year after transcatheter closure of atrial septal defects using the amplatzer septal occluder. Pediatric Cardiology 2003;24:259-62.

22 Cottens D, Van de Bruaene A, Troost E, et al. Influence of percutaenous transcatheter closure of an atrial septal defect on the atrioventricular conduction. Acta Caridologica 2011;66:309-14.

23 Wilson NJ, Smith J, Prommete B, et al. Transcatheter closure of secundum atrial septal defects with the amplatzer septal occluder in adults and children-follow-up closure rates, degree of mitral regurgitation and evolution of arrhythmias. Heart, Lung and Circulation 2008;17:318-24.

24 Schenck $\mathrm{MH}$, Sterba R, Foreman CK, et al. Improvement in noninvasive electrophysiologic findings in children after transcatheter atrial septal defect closure. The American Journal of Cardiology 1995;76:695-8. 